\title{
Geographies of adolescent distress: A need for a community-based psychosocial care system in Nepal
}

\begin{abstract}
Nawaraj Upadhaya ${ }^{1}$, Carola Tize ${ }^{2}$, Ramesh P. Adhikari ${ }^{3}$, Dristy Gurung ${ }^{4}$, Ruja Pokhrel ${ }^{5}$, Sujen M. Maharjan ${ }^{6}$ \& Ria Reis ${ }^{7}$
${ }^{1}$ MA, MSc, Project Coordinator at the Department of Research, Transcultural Psychosocial Organization Nepal, Kathmandu, Nepal, ${ }^{2}$ MSc, PhD Candidate at the Amsterdam Institute for Social Science Research (AISSR) Department of Anthropology, University of Amsterdam, Amsterdam, The Netherlands, ${ }^{3} \mathrm{MA}$, MPhil, Research Coordinator at the Department of Research, ${ }^{4} \mathrm{MSc}$, Project Coordinator at the Department of Research, ${ }^{5} \mathrm{MA}$, Senior Research Officer at the Department of Research, Transcultural Psychosocial Organization Nepal, Kathmandu, Nepal, ${ }^{6} \mathrm{MA}$, Programme Manager at the Mental Health and Care Practices (MHCP) Department, Action Contre la Faim (ACF), Kathmandu, Nepal, ${ }^{7} \mathrm{MA}$, PhD, Professor, Department of Public Health and Primary Care, Leiden University Medical Center, the Netherlands; Associate Professor, Department of Anthropology, University of Amsterdam, the Netherlands; Honorary Professor at the Children's Institute, University of Cape Town, Cape Town, South Africa
\end{abstract}

\section{Abstract}

This paper presents the findings of an ethnographic study conducted among high school students in Nepal. Participant observations, in-depth interviews and focused group discussions were conducted among 35 students (20 girls and 15 boys). The findings suggest three geographies (home, school and community), where adolescents experience distress. Common experiences of adolescent distress included discrimination, domestic violence, heavy workload, poverty, bullying, physical punishment, unsupportive behaviour of the parents and teachers and a lack of basic materials. These findings largely support Bronfenbrenner's socio-ecological model, emphasising the complex reciprocal interactions between the individual and his/her immediate environment. They also suggest that not only a reciprocal relationship between the sub-systems of the ecological model, but also a 'mobility' between and among these sub-systems affects the individual's emotional-relational well-being. We argue that the micro-systems in which children grow up not only have a social dimension, but a spatial dimension as well. Building on this insight, a five building-block intervention model is presented to help address adolescent distress.

Keywords: Adolescents, geographies of distress, Nepal

\section{KEY IMPLICATIONS FOR PRACTICE}

- Given adolescents' mobility between home, school and community, a community-based psychosocial care system is proposed that also addresses distress related to the in-between travelling spaces.

- Such a system would comprise family support, peer-to-peer education, community mobilisation and school mental health.

- School counsellors should provide counselling in the school, but also use home visits and in-between travelling spaces as implementation sites for interventions.

\section{INTRODUCTION}

Experiencing psychological distress is common to humans in all settings and economic circumstances but more prevalent in resource-poor settings. Distress, which implies a notion of suffering (Woodgate \& McClement, 1998), may arise as a result of a mismatch between a person's needs and the opportunities available in the environment (Eccles et al., 1993). Emotional distress experienced during adolescence can produce tensions between an adolescent's own lived experiences and societal expectations that may exacerbate their distress (McQueen \& Henwood, 2002). The World Health Organization World Mental Health Survey found that childhood adversities have a strong

\begin{tabular}{|l|l|}
\hline \multicolumn{2}{|c|}{ Access this article online } \\
\hline Quick Response Code: & Website: \\
& www.interventionjournal.org \\
& \\
\end{tabular}

association with mental disorders at all stages of life (Kessler et al., 2010). A study, among adolescents of five developing countries found that $10.5 \%$ reported having mental health problems and among them conduct and emotional problems were the most prevalent (Atilola, Balhara, Stevanovic, Avicenna, \& Kandemir, 2013). Similarly, the Nepal Adolescent and Youth Survey 2010/2011

Address for correspondence: Mr. Nawaraj Upadhaya, Department of Research, Transcultural Psychosocial Organization Nepal, Kathmandu, Nepal.

E-mail: navarajtpo@gmail.com

This is an open access journal, and articles are distributed under the terms of the Creative Commons Attribution-NonCommercial-ShareAlike 4.0 License, which allows others to remix, tweak, and build upon the work non-commercially, as long as appropriate credit is given and the new creations are licensed under the identical terms.

For reprints contact: reprints@medknow.com

How to cite this article: Upadhaya, N., Tize, C., Adhikari, R. P., Gurung, D., Pokhrel, R., Maharjan, S. M., \& Reis, R. (2019). Geographies of adolescent distress: A need for a community-based psychosocial care system in Nepal. Intervention, 17(1), 76-85. 
Upadhaya et al.: Geographies of adolescent distress in Nepal

conducted in 72 out of the 75 Nepali districts suggested that $14 \%$ of adolescents are suffering from at least one type of psychosocial problem (Adhikari, Upadhaya, Suwal, Shrestha, \& Sube, 2016). One indicator of distress among adolescents is a high prevalence of suicide. Epidemiological data on suicide rates in Asia are not very reliable, and the problem is often underreported and not stratified for adolescents (Jordans et al., 2014). However, a retrospective study of suicide between Nepali children and adolescents showed that out of 2172 documented suicides between 4 and 21 years of the age, 92.4\% were adolescents (Mishra, Shrestha, \& Poudyal, 2013). In Nepal, every year many adolescents die by suicide as a result of failing their school leaving certificate examination (Kathmandu Post, 2010; Nepalnews.com, 2013; Sambadmedia.com, 2014). A second indicator for the high level of distress among Nepali adolescents is the annual outbreaks of mass hysteria among school children. Groups of adolescents, especially girls, collectively complain of abdominal pain and headaches, showing symptoms such as dizziness, hyperventilation, nausea and fainting. These uncontrolled outbreaks often require the administration to close schools for indefinite periods of time (The Himalayan Times, 2010).

There are multiple causes for the high degree of distress among Nepali adolescents. Over the past few decades, political instability, long-lasting injustice and structural violence have given rise to conflicts in Nepal; the most prolonged was the Maoist conflict, which lasted for 10 years (1996-2006) and claimed the lives of more than 13,000 people (Russell, 2012). The resulting combination of prevailing social injustice, a damaged social fabric, poverty and human rights violations is a major source of emotional distress for adults and children alike (Jordans, Tol, \& Komproe, 2011). Although the caste system is no longer legally enforced in Nepal, in practice it is still very much in effect and causes deep inequity. Caste and religion determine the social hierarchy, and children from lower castes often face social discrimination and ill treatment, which creates psychological distress and frustration.

Due to the high prevalence of emotional distress and suicide among Nepali adolescents, there is a need to understand the adolescents' perspectives about their distress and how to help them to prevent, reduce and overcome their psychosocial and mental health problems.

The ecological model developed by Bronfenbrenner is a suitable framework to map both adolescents' distress and their resources to cope with it. Its central principle is that a child's development and well-being are influenced by the entire socio-ecological system in which the child is embedded. A child is embedded in different micro-systems (e.g. the family, community or school) in which he/she interacts with significant others. Interactions between micro-systems constitute the meso-system and impact a child's wellbeing, for instance, when parents and teachers meet to discuss the child's development. More distant structures, such as the extended family or a parent's workplace, form the exo-system and may indirectly influence the conditions in which the child grows up. Finally, at the macro level, overarching processes and systems of ideas (broader political context, socio-economic conditions and available services, cultural values and norms) also impact how children grow up (Berckmoes, De Jong, \& Reis, 2017; Elder \& Shanahan, 2006). In his later work, Bronfenbrenner (1994) included a fifth system, the chrono-system, acknowledging the importance of time processes both over the individual's life course as well as socio-historical transitions and events. As the topic of our exploratory study is how adolescents experience, perceive and act upon distress, we used the socio-ecological framework to map the relevant contexts in which children interact with others, and we focused on the micro-systems of the school, the family and the community and interactions at the mesolevel.

\section{Materials AND MethODS}

\section{Setting}

Nepal, a multi-ethnic, multilingual Himalayan country, is one of the poorest in the world. A report from UNDP (2015) revealed that approximately $25.2 \%$ of the people live below the national poverty line and $23.7 \%$ earn less than 1.25 USD per day. The government spends only $4.7 \%$ of the gross domestic product on education, and the adult literacy rate in 2014 was $57.4 \%$. The mean years of schooling for females are $2.3 \%$ and $4.5 \%$ for males, and $39.6 \%$ drop out and therefore do not complete primary level education. The student-teacher ratio in primary schools is 24:1 (UNDP, 2015). This ethnographic study took place in a government school located in a rural part of the Lalitpur district whose total population is 468,132 with $51 \%$ males and $49 \%$ females (CBS, 2012). Lalitpur is one of the three districts that compose the Kathmandu Valley, including the capital and largest urban centre in Nepal. Despite its proximity to the largest urban centre in the country, Naranarayan High School (pseudo name for the school) is considered rural, as it is on a steep mountain-side in the Kathmandu Valley and overlooks the city below. It is difficult to reach by a car or motorcycle and is mostly accessed from the surrounding villages via steep walking trails winding through dense forests.

\section{Study population and sampling}

Research participants were students from the three upper level classes of Naranarayan High School in grades 8 to 10 . Like most other Nepali government high schools, particularly in rural villages, Naranarayan is poorly resourced with a high number of adolescents from lower socio-economic backgrounds. The school was purposively selected and is representative of other high schools in Nepal. In addition, the first author had already established contact with the school, making it feasible to conduct the school ethnography within the short time frame available for the study.

A total of 111 adolescents at Naranarayan High School were 13 to 18 years old and eligible for inclusion. Our sample represented multiple caste and ethnic groups [refer to Table 1]. A stratified random sample of 30 adolescents was selected for focus group discussions (FGDs) and individual interviews to prevent gender or caste bias. 
Upadhaya et al.: Geographies of adolescent distress in Nepal

\begin{tabular}{lccc}
\hline \multicolumn{3}{l}{ Table 1: Demographic data of the research participants } \\
\hline Variable & Values & $\boldsymbol{N}=\mathbf{3 5}$ & $\%$ \\
\hline \multirow{2}{*}{ Gender } & Girls & 20 & 57.14 \\
& Boys & 15 & 42.86 \\
Age & $13-15$ & 12 & 34.29 \\
& $16-18$ & 23 & 65.71 \\
Caste/ethnicity & Dalit & 6 & 17.15 \\
& Chhetri & 14 & 40.00 \\
& Janajati & 13 & 37.14 \\
& Brahmin & 2 & 5.71 \\
\hline
\end{tabular}

Note: $N=35$ was total number of research participants.

Four separate lists according to caste were made, and each student was assigned a number in front of his/her name. Then, the list (without names) was sent to an anonymous assessor, and he was asked to select 12 adolescents from Chhetri, 12 from Janajati, five from Dalit and one from the Brahmin caste (based on the percentage of castes represented at school). During activities outside of the school, such as picnics and community walks, fieldwork relationships gradually developed with adolescents outside of the FGDs and interview sample, resulting in five more adolescents volunteering to participate in the study, resulting in 35 research participants (20 girls and 15 boys).

\section{Data collection}

The data were collected in May and June 2011 and during several follow-up visits to the school and community in 2012 and 2013. In addition to participant observations, the first author conducted community walks and informal discussions with parents, teachers and adolescents, and FGDs and in-depth interviews with the adolescents.

\section{Participant observation}

The ethnographic approach was preferred because it (through participant observation) allows the context and the rational of the responses provided by the adolescents to be assessed in their day-to-day environment. To identify the sources of distress and adolescents' strategies to manage distress, considerable time was spent observing the adolescents' day-to-day life, particularly their management of situations that produce distress and their use of existing resources to reduce distress. Peer communication and interactions with teachers and senior adolescents were observed in both formal and informal settings. Formal settings included the classroom, the teacher's common room, as well as interactions at the school water tap, the toilets and veranda. The distressful events identified during class and in other formal settings were further explored by in-depth conversations with the adolescents in informal settings, such as picnic spots, the playground and the walking paths to school and football matches.

\section{Focus group discussions}

Three FGDs with boys and three with girls were conducted. Each FGD had 6 to 8 participants. The aim was to understand how knowledge about distress is constructed, understood and transmitted in social interactions.

\section{Semi-structured in-depth interviews}

The first author conducted 12 in-depth interviews with boys who had participated in FGDs to gain retrospective account of distressful events and insights into meaning, values and opinions regarding their distress. Individual indepth interviews with girls were not possible, as in Nepal it is considered culturally inappropriate for a male researcher to separately interview a young unmarried female.

\section{Data analysis}

The audio recordings were transcribed into Nepali. The data were anonymously analysed by deleting personal and school identifiers. We followed a two-stage analysis procedure (systematic clustering of data based on Bronfenbrenner's ecological model-home, school and community and a reflection on findings with the second and sixth authors, who also conducted research in the same village on another topic). Systematic clustering of related data was performed to identify what Good (1998) has called semantic networks - interconnected domains of meaning that constitute a culturally or context-specific experience of illness or distress (Good, 1998). Close reading of the Nepali transcripts, English field and reflection notes led to the identification of peers as an important micro-system as well as three separate but interconnected geographical settings (home, school and the community), where adolescents experienced distress. Data categorised in these domains were further analysed iteratively with open and axial coding. Constant comparison of the themes with Bronfenbrenner's ecological model lead to an emerging concept of 'geographic mobility of adolescents' distress in Nepal, which is explained below.

\section{Ethics approval and consent to participate}

As required by the Sociology and Anthropology Department of the University of Amsterdam, ethical guidelines of the American Association of Anthropologists were followed. In Nepal, the Naranarayan School administration, teachers and parents provided permission for the research. For both the FGDs and in-depth interviews, the adolescents provided informed verbal consent. One of the parents (mother or father) consented their child's participation and for children whose parents were not available, the teachers acted as a proxy. Adolescents were informed about the psychosocial support services should they require any assistance during or after the study period. The names of the school and the respondents have been changed to protect their privacy and minimise possible stigmatisation.

\section{RESULTS}

\section{Experiences of distress at home}

Distress in the home is distinguished from other distress, as it forms early childhood experiences and has a particularly high value in shaping a person's world-view. The most common stressors in the home were experienced as distress due to domestic violence, substance abuse, neglectful and unfriendly parental behaviour, family poverty and family debt. 
Upadhaya et al.: Geographies of adolescent distress in Nepal

\section{Domestic violence}

Domestic violence can have severe consequences on a child's development. In particular, many adolescents identified distress regarding paternal violence towards mothers and children. Shiva (boy, age 14) said:

'My father beats my mother so badly every time he comes home after work. The beating became so bad that my mother could no longer take care of the children, so I was sent to my maternal uncle's house.'

In Nepali society, a father is an authority figure. Fathers who have arguments in the community and lack the power to defend their position or argue back (e.g. those who are low caste or in debt) can release their anger at their family and displace it upon their wives and children by beating them. Supriya (girl, age 14) said:

'My father had a big dispute at his office; therefore, he had to leave the job. He now pours his office anger to me, my sister and my mother.'

\section{Substance abuse by parents and family members}

The adolescents identified substance abuse, particularly the use of locally made alcohol, as a cause of distress, particularly for the Tamang and Dalit caste (In Nepal, caste is mainly grouped in four broader categories, Brahmin, Chhetri, Janajati and Dalit. The Tamang caste falls within the Janajati category). The use of homemade alcohol is common in the study area, especially in Tamang families, where it is culturally accepted. During the research, many adolescents expressed concern and experienced distress because of domestic violence triggered by alcohol consumption. Basanti (girl, age 15) reported:

'My mother, grandmother and father all used to drink; now after having jaundice, grandmother has stopped drinking. Mother also stopped once she converted to Christianity, but my father is still drinking.'

The availability of alcohol in the village and excessive drinking by fathers is at the root of many social problems, such as fights, disputes, domestic violence, poverty and unemployment. One of the Tamang boys in an FGD said,

'My father drinks alcohol and makes disputes with my mother and other family members; his behaviour disturbs my studies'.

\section{Parents' understanding of children's educational needs}

There is a vast gap between the parents' understanding of education and children's real educational needs. The findings revealed that most parents want their children to be educated, but they do not understand the extent of their children's hard work and the number of educational materials children require to excel in their exams. The following FGD excerpt with boys from grade 9 is illuminating.

'Parents don't understand our need for educational materials. When we ask for money for pens and exercise books parents don't listen, even if they listen they try to delay.
Because of the behaviours of our parents, we experience problems at school when our teachers asks for the right notebook for homework.'

\section{Loans}

In Nepali society, families openly share and discuss the stress of finances within the family. As a result, parental stress is also shared with their children. Taking out family loans is a common practice to survive rough times and significantly stressful for the adolescents. Many adolescents showed great sensitivity towards parental pain and sorrow and wished they could help them overcome the problem. The most severe effect of extensive family loans is the adolescents' withdrawal from school to work and help to repay an outstanding loan. The stress associated with family loans greatly impeded their studies. Sanjay (boy, age 15) explained

'I feel sorry for my mother and think I should leave the school and help her repay the loan, but then I feel if I leave the school, my future will be dark, and I will have to do hard labour like my mother. I have not been able to help her, and I have not been able to concentrate on my studies fully. It's actually a terrible situation emotionally.

Affluent people in the community often provide loans to poor people. The high interest and short time to repay these loans cause parents immense distress, which is transmitted to their adolescent children. This also strains community relations, as gossip and rumours increase pressure and shame on individual families with outstanding loans.

Sundar's (boy, age 13) experience is an example of distress transmitted from parents to their child and a collective feeling of suffering:

'My father died because of cancer. He was on medication for seven months. We ran out of money, and we took a loan and now it's a problem to repay it. Everybody in the family is tense - I also feel tension!'

\section{Experiences of distress at school}

Poverty, family status and particularly parental experiences of discrimination have effects on how children experience stress in school and the community. The three major causes of distress in the home (poverty, violence and workload) impact adolescents in their schooling. Because of the lack of educational materials, adolescents may not manage to complete school assignments, and material deficits irritate teachers, which sometimes results in physical punishment. All these factors ultimately trigger distress among adolescents.

\section{Teachers' behaviour}

Almost all adolescent participants in the research, in both formal and informal settings, complained about their teachers' behaviour. According to Bishnu (boy, age 16), the teachers' behaviour is discriminatory:

'Our teachers scold us without any big issue. Most of the teachers support only the students who are better at the study. The poor students don't get enough attention from the teachers. While marking the exam papers, some 
Upadhaya et al.: Geographies of adolescent distress in Nepal

teachers favour their favourite students and give full marks even if there are slight mistakes and for the students who are not their favourite, the teachers carefully look for the mistakes of the students in order to reduce the marks.'

Adolescents are particularly fearful of their teachers on the days when they have not completed their homework. Adolescents related how intimidated they felt when they were sent out of the classroom for reasons to do with homework. The adolescents feel deeply hurt and emotionally deserted by teachers' humiliating behaviour. This is clear from the following statement by Shahasi (boy, age 14):

'Teachers don't try to understand the problem of the students. They know the fact that we are from poor background, (. . .) but still when we have not been able to have new school dress and come to school in out[side] dress, teachers tell us to come only when we have new school dress, parents can't afford to buy on time and teachers don't allow us to enter the classroom; we are facing a double burden.'

Some adolescents complained that when they tell the teachers they do not understand the topic, the teachers say, 'I have explained so many times; why haven't you been concentrating? You will never understand'. Some teachers make comments that hurt adolescents deeply, such as ' $Y o u$ don't have the brains capable of studying, better work as Khalasi' (bus conductor). In Nepal, most people think that Khalasi are uneducated, backward and uncivilised.

Such behaviour by teachers causes significant distress for many students, also because their low social position prevents them for protesting in the moment, but they show their resentment, and agency, by either deliberately not doing the homework or not returning to school the next day.

\section{Physical punishment (beating for betterment)}

During the entire fieldwork period, the first author did not see teachers beating students, but in all interviews, beating was mentioned as a major distressful event. Some of the students accused some teachers of beating so badly that they became unconscious or sustained injuries to their hands and back. Harikrishna (boy, age 15) said:

'I had big blisters on my palm when a teacher hit me hard. I was irritated by the teacher at that moment but after sometime, when I reflected back, I thought our teachers' intention is not bad; they scold us, beat us and control us only for our brighter future so we should not think negative about our teachers.'

There is a certain level of acceptance of beating children in Nepali society. The parents, teachers and the adolescents think that some level of physical punishment is necessary to bring desired outcomes in adolescents' lives.

Although adolescents complained about being beaten, they did not question the teachers' good intentions. All expressed that their teachers' intention was positive.

\section{Experiences of distress in the community}

The roads to the school pass through a dense forest and are slippery during rainy seasons, dusty during the dry seasons and children face fear of wild animals and the possibility of lurking strangers along the paths. Bullying and discrimination based on family status, poverty, caste and ethnicity were mentioned as causes of distress for adolescents.

\section{Bullying}

Bullying presents a source of distress and can have lasting psychosocial effects if continued over a long time. In a community where social stratification, hierarchy and prestige play an important role in determining power and supremacy, bullying becomes a common phenomenon, especially for adolescents from poor family backgrounds and with low intellectual ability. Bullying takes place for both genders. When a boy talks nicely to a girl, other boys bully him, and when a girl becomes a boy's good friend, other girls bully her. Ramesh (boy, age 14) said:

'When I don't know how to do my homework, I go and ask a female friend, but at that time my male friends tease me that she is my girlfriend; this makes me angry and discourages me from approaching her again.'

Adolescents bully other adolescents who are punished by the teachers or because of their social position.

While travelling from home to school and back, senior adolescents bully the junior ones by saying, 'you are the son of a drunkard, pauper', 'you are the son of a terrorist' (for several years, the government of Nepal treated the Nepal Communist Party, the Maoists, as a terrorist organisation, so the villagers used the term 'terrorist' to intimidate those who had joined the Maoist party), 'your father is crazy', 'your nose is like a monkey' or 'you speak with your nose not with your mouth'. When junior adolescents start confronting their tormentors, they are beaten by the seniors.

For some adolescents, bullying is much more painful than physical punishment, as in the words of Ganesh (boy, age 13):

'Physical pain does not last long. When wounds get healed, pain disappears, but bullying hurts much more than physical injuries; it stays inside your heart and pinches you over and over again. At times bullying is so painful that I can't stand, tears start flowing.'

\section{Discrimination (at school and at home/community)}

Distress can also result from discriminatory behaviour of peers, teachers and parents. Community members characterise adolescents based on their family status, caste and ethnic origin, and adolescents from lower social strata feel discriminated in their own community. Peers often compare each other and discriminate against others based on poverty levels and family environments. Comparisons such as 'you are poor, I am rich', 'I go to an expensive school while you study in an ordinary school', 'I belong to a higher caste and you belong to a lower caste', 'your father is a drunkard and my father is sober' are common in the village. 
Upadhaya et al.: Geographies of adolescent distress in Nepal

The boys in Naranarayan School feel that they are discriminated against by teachers; they believe that the teachers generally favour girls, by accepting any demands by girls, whereas they do not bother with the boys' interests and wishes. Chanchal (boy, age 15) said:

'Teachers beat girls so softly thinking that their body is made up of bones and flesh, but teachers beat the boys thinking that a boy's body is made up of stone and mud.'

Although boys complained about the teachers' discriminatory behaviour in schools, girls complained about their parents' discriminatory behaviour at home.

In Nepal, generally, couples prefer sons over daughters among others, because sons are expected to take care of their parents when they age, whereas daughters will marry into another family. As a result, many daughters felt that their parents favour their sons. Female adolescents felt discriminated and neglected by their parents' behaviour. Priyanka (girl, age 17) said:

'At home my younger brother makes mistakes, but our parents never beat him, rather they scold me and beat me.
They love him so much that I feel discriminated [against].'

\section{Adolescents' own problem-analysis model and geographies of distress}

The adolescents' own problem-analysis model emerging from our analysis points at distress experienced at various socio-ecological levels [Figure 1]. The three micro-systems (home, school and community) where children experience distress not only have social dimensions (as described in social-ecological theory) but also spatial dimensions. These micro-systems are specific geographical sites, and in their daily lives while shifting from one site to another, children take their distress with them. Distress in one geographic setting triggers additional distress in the same or another setting. For example, family poverty may trigger domestic violence and discrimination in the school and the community [Figure 2]. The in-between geographies (the roads that children travel) also are a source of specific distress (e.g. being bullied or sexually harassed by peers outside the control of parents or teachers) and resources to

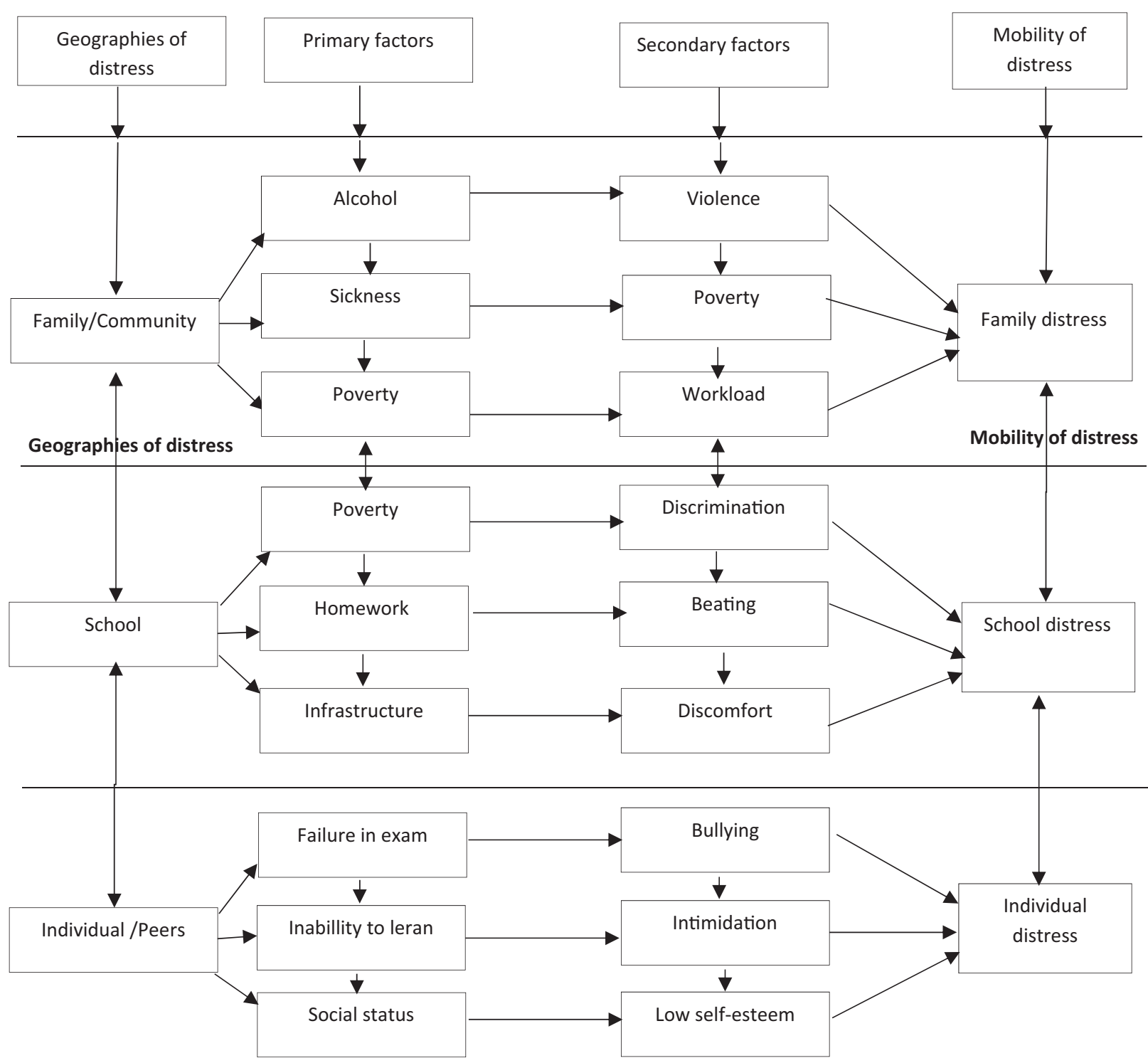

Figure 1: Adolescents' own problem analysis model 
Upadhaya et al.: Geographies of adolescent distress in Nepal
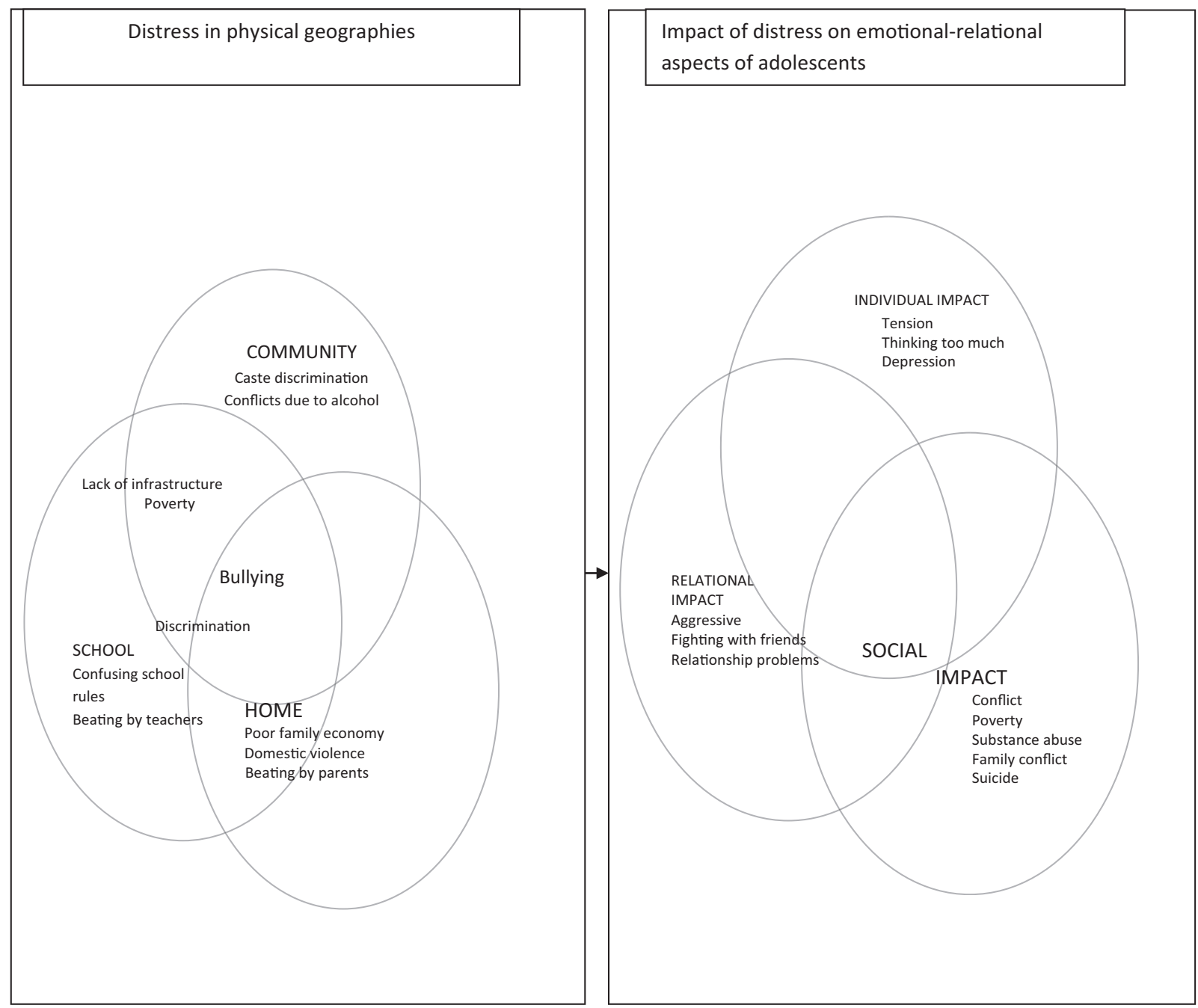

Figure 2: Physical geographies of distress and their impact on emotional-relational aspects of adolescents

cope with distress (e.g. walking and talking and having fun with friends).

For adolescents, distress originating from different physical geographies gives rise to individual (e.g. tension, worry and depressive feelings), relationship (e.g. constant fighting with friends and family members) and societal problems (e.g. the excessive use of alcohol and substances by parents and family members, poverty and societal conflict).

\section{Discussion}

The findings suggested that Nepali adolescents experience significant emotional distress rooted in the geographies of home, school and community. Their experiences of distress at home and in the community were related to domestic violence, their family's heavy workload, a lack of materials for meeting basic needs, difficulty repaying loans and conflict in their family or with neighbours. Discrimination, bullying, physical punishment and lack of materials were common distress experiences both at home and in the community and school. The teachers' behaviours and teaching styles were typical school-related distress experiences. Below we discuss two major themes from the findings: first, the socio-cultural origin of adolescent distress and, second, the geographic mobility of adolescent distress. Finally, we propose a community-based psychosocial care model focused on a spatial approach within micro-systems to address adolescent distress in Nepal.

Young people use culturally appropriate concepts to voice their distress (McQueen \& Henwood, 2002), as this creates acceptance and prevents ridicule. Most distressful situations expressed by the Nepali adolescents are associated with the social conditions of caste, ethnicity, poverty, alcohol abuse and domestic violence. In Burundi, Jordans et al., (2011) found that children's emotional distress was linked to 'broken families', and caused by physical neglect and maltreatment by extended family members. This reflects an assumption that distressful situations are related to social conditions and interactions, and how reactions to these distressful situations are socially patterned is also part of the socio-genesis of their distress. The general acceptance of beating for betterment and keeping distressful experiences to oneself (silencing the distress) are socially embedded reactions that allow adolescents to deal with these distressful situations, whereas it is beyond their power to change the underlying social conditions.

The adolescent explanatory model of distress experiences is also rooted in the socio-cultural context. Recognising the socio-cultural determinants of psychosocial problems, the Inter-Agency Standing Committee (WHO, 2007) guidelines 
Upadhaya et al.: Geographies of adolescent distress in Nepal

on psychosocial and mental health in emergencies emphasises social strategies to promote psychosocial well-being. Similarly, Akello, Reis, and Richters (2010) and Kohrt et al. (2010) believe that the explanatory models of distress experiences of adolescents at various ecological levels (the individual, home, school and the community) must be situated and analysed within their socio-cultural context.

The study findings show that adolescent distress is spread over several ecological levels. This is in line with Bronfenbrenner's (1979) ecological model, where children mainly interact at the level of micro-systems but indirectly get affected from the meso- and exo-systems. The findings also suggest that there is a component of mobility between and among these micro-systems (multiple geographical and social contexts in which adolescents interact) when adolescents and their accumulated distress travel from one geographical space to another. We call this 'geographic mobility of distress'. Although Bronfenbrenner (1994), in his later work, added the dimension of time by proposing the concept of chrono-system with its three components over time - (1) the developing person, (2) changing environment and (3) their proximal processes - the ecological model lacks a spatial dimension. Our findings suggest that micro-systems are social systems with specific spatial characteristics. The core microsystems in which adolescents develop (the home, school and the community) are located in specific geographies from where adolescents accumulate distress and travel from one micro-system to another. This shows that both adolescents and their distress have a geographical movement. Focusing on the spatial dimension, on the 'geographic mobility of distress', allows an exploration of the

\section{Psychosocial care system building blocks}

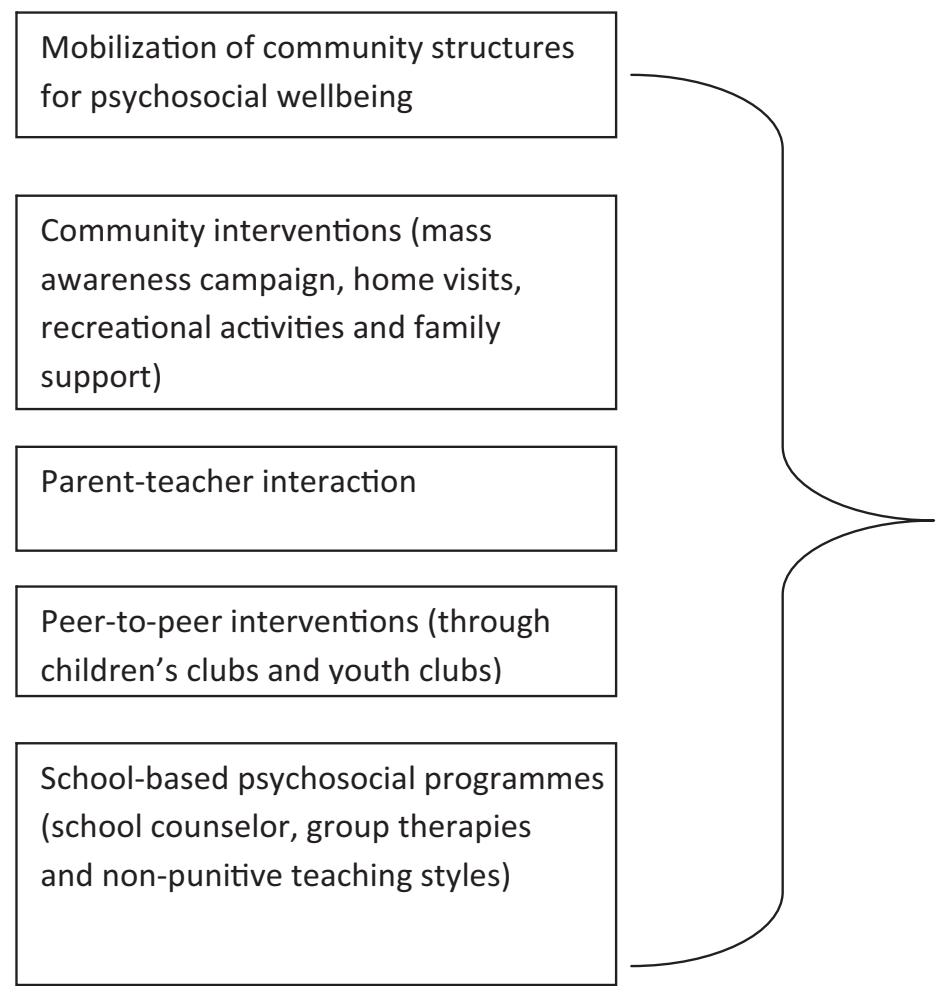

movement of distress between bounded spaces, such as home, school and community.

The efforts to address adolescent distress should also be examined within these three geographies as well as in between travelling spaces. Particularly in these in-between spaces, fluid and potentially powerful social relations are formed, specific stressors may occur and specific coping mechanisms may be used all out of sight of adult-dominated domains. Peers do emerge as an important microsystem where children experience distress while travelling with peers, but the geography of the peer micro-system is ambivalent, as it is both in the school and in the geographies between home and school. We hypothesise that it is this geographic fluidity of the peer system over the boundaries of micro-systems dominated by adults (home, schools and community) that can make peer processes such powerful instigators of distress. Because of this fluidity (lack of specific geographic place), distress originating from peer micro-systems is difficult to control and, therefore, calls for interventions targeting the issues that happen among peers in the travelling spaces. Our findings suggest that these three geographies (home, school and community) and the spaces between them can be effective implementation spaces for a community-based psychosocial care model of family support, peer-to-peer education, community mobilisation and school mental health [Figure 3]. Opportunities exist to develop psychosocial programmes for children considering the geographical spatial dimension, as geographies of children are emerging as a sub-discipline in the field of geography, and many studies have been done on emerging themes of children's play and mobility (Skelton, 2009).

\section{Expected outcomes}

\section{Increased detection of psychosocial distress}

Non-medicalisation of the problems

Timely referral in cases of other health and social needs

Psychosocial-friendly home, school and community environment

Figure 3: Proposed community-based psychosocial care system 
Upadhaya et al.: Geographies of adolescent distress in Nepal

\section{Strengths and limitations}

The study has captured the lived experiences of adolescents through several qualitative methods and informal sharing, which is its strength, but due to the sample size the findings cannot be generalised for adolescents from other parts of Nepal. The fact that the researcher is an adult male hampered in-depth inquiries into the problems specific to adolescent girls. It was not possible to hire a female field worker to conduct the FGDs due to a lack of resources, but this would be advisable for a follow-up study.

\section{Way forward}

Given the social construction of adolescent distress and the geographical mobility between and among home, school and community, we propose developing and strengthening a community-based psychosocial care system that also captures the interventions for the in-between travelling spaces [as presented in Figure 3].

There are several prerequisites for the successful implementation of the proposed community-based psychosocial care system. First, a school counsellor who can provide individual and group counselling services and make home visits to support both the children and families is necessary. In each school, a separate room is required for children to speak privately to the counsellor. The school's already existing extracurricular activities can be assessed and redesigned to address the adolescents' psychosocial needs, particularly their distress due to the spatial dimension of travelling spaces. Second, basic psycho-education is required for the school staff and students, parents and community members on distress related to in-between travelling spaces and how it can be minimised. Particular emphasis could be placed on the consequences of difficulties in the home, school and community environments that impact children's cognitive development and school performance. School staff, with basic techniques of identifying and addressing uncomplicated psychological problems of childhood (Pillay \& Lockhat, 1997), could intervene and aid students in their development and problem solving. Third, regular home visits by a school counsellor are needed to identify the real problems faced by the children and their family members. These home visits would strengthen the meso-system level and provide the families with psycho-education and community mediation activities. During the home visits, the counsellor could also use travelling spaces, such as roads and public resting places, as implementation spaces to explore adolescents' distress and intervene to reduce such problems. Fourth, as bullying by peers while travelling from one place to the next is one of the major sources of adolescents' distress, the child club and youth club members can be given training and regular coaching on how to help peers who are distressed. This peer-to-peer intervention would help reduce distress that is caused by bullying and intimidation by fellow adolescents. Fifth, a quarterly formal parent-teacher interaction programme could be organised to discuss the adolescents' behaviour, academic performance, psychosocial problems and the role that parents and teachers can play to support them.

\section{Conclusions}

The findings suggest that distress is generated and experienced across all micro-systems (family, peer, school and community), which emotionally and relationally impacts adolescents. As sources of distress move from one geography to the next, the distress moves as well. Distress is not static, rather it is mobile and affecting/or being affected by several geographies simultaneously. This geographical dimension (distress in in-between spaces) of distress, to our knowledge, is lacking from the ecological models that psychosocial practitioners and researchers use. Therefore, community-based integrated approaches are needed that implement interventions across children's micro-systems and consider the travelling in-between spaces.

\section{Acknowledgements}

We would like to thank students, teachers and parents for their participation in the study. We would also like to thank Julia Challinor for reviewing the manuscript. This paper is based on an MSc thesis submitted to the University of Amsterdam. The paper was presented at Annual Kathmandu Conference on Nepal and Himalaya in July, 2014.

\section{Financial support and sponsorship}

The first author was supported by a fellowship from Netherlands Fellowship Program (NFP).

\section{Conflicts of interest}

There are no conflicts of interest.

\section{REFERENCES}

Adhikari, R. P., Upadhaya, N., Suwal, B. R., Shrestha, M. P., \& Subedi, P. K. (2016). Factors associated with perceived psychosocial problems and help-seeking practices among adolescents in Nepal. Journal of Population and Social Studies, 25(1), 1-10.

Akello, G., Reis, R., \& Richters, A. (2010). Silencing distressed children in the context of war in Northern Uganda: An analysis of its dynamics and its health consequences. Social Science and Medicine, 71, 213-220.

Atilola, O., Balhara, Y. P. S., Stevanovic, D., Avicenna, M., \& Kandemir, H. (2013). Self-reported mental health problems among adolescents in developing countries: Results from an international pilot sample. Journal of Developmental and Behavioral Pediatrics, $34,129-137$

Berckmoes, L. H., De Jong, J. T. V. M., \& Reis, R. (2017). Intergenerational transmission of violence and resilience in conflict-affected Burundi: A qualitative study of why some children thrive despite duress. Global Mental Health, 4, e26.

Bronfenbrenner, U. (1979). The ecology of human development: Experiments, by nature and design. Cambridge, MA: Harvard University Press.

Bronfenbrenner, U. (1994). Ecological models of human development. In International Encyclopedia of Education (Vol. 3, 2nd ed.). Oxford: Elsevier. Reprinted in: M. Gauvain, \& M. Cole, (Eds.), Readings on the development of children (2nd ed., pp. 37-43). NY: Freeman.

CBS. (2012). National population and housing census 2011 Kathmandu. Nepal: Central Bureau of Statistics.

Eccles, J., Midgley, C., Wigfield, A., Buchanan, C., Reuman, D., \& Flanagon, C., et al. (1993). Development during adolescence: The impact of stage-environment fit on young adolescents, experiences in schools and in families. American Psychologist, 48(2), 90-101.

Elder, G. Jr., \& Shanahan, M. (2006). The life course and human development. In: W. Damon, \& R. M. Learner, (Eds.), Handbook of child psychology (Vol. 1). Hoboken, NJ: John Wiley \& Sons, Inc. 
Upadhaya et al.: Geographies of adolescent distress in Nepal

Good, B. J. (1998). The heart of what's the matter. The semantics of illness in Iran. Amsterdam: Het Spinhuis.

Jordans, M. J., Kaufman, A., Brenman, N. F., Adhikari, R. P., Luitel, N. P., \& Tol, W. A., et al. (2014). Suicide in South Asia: A scoping review. BMC Psychiatry, 14(1), 358. 10.1186/s12888014-0358-9

Jordans, M., Tol, W. A., \& Komproe, I. H. (2011). Mental health interventions for children in adversity: Pilot-testing a research strategy for treatment selection in low-income settings. Social Science \& Medicine, 73, 456-466.

Kathmandu Post. (2010). Youth more prone to suicide (November 11), Kathmandu Post. Retrieved from http://www.ekantipur.com/thekathmandu-post/2010/09/10/top-story/youth-more-prone-to-suicide/ 212596/

Kessler, R. C., McLaughlin, K. A., Green, J. G., Gruber, M. J., Sampson, N. A., \& Zaslavsky, A. M., et al. (2010). Childhood adversities and adult psychopathology in the WHO World Mental Health Surveys. The British Journal of Psychiatry, 197(5), 378-385.

Kohrt, B. A., Jordans, M. J., Tol, W. A., Perera, E., Karki, R., \& Koirala, S., et al. (2010). Social ecology of child soldiers: Child, family, and community determinants of mental health, psychosocial well-being, and reintegration in Nepal. Transcultural Psychiatry, 47(5), 727-753.

McQueen, C., \& Henwood, K. (2002). Young men in "crisis": Attending to the language of the teenage boy's distress. Social Science and Medicine, 55, 1493-1509.

Mishra, N., Shrestha, D., \& Poudyal, R. B. (2013). Retrospective study of suicide among children and young adults. Journal of Nepal Pediatric Society, 33(2), 110-116.
Nepalnews.com. (2013) Girl commits suicide after failing SLC supplementary exams. Nepalnews.com.

Pillay, A. L., \& Lockhat, M. R. (1997). Developing community mental health services for children in South Africa. Social Science \& Medicine, 45(10), 1493-1501.

Russell, A. (2012). Transitional justice and the truth commission in Nepal senior honors projects, Paper 272. USA: University of Rhode Island.

Sambadmedia.com. (2014) Three girls have committed suicide in different districts after failing the SLC (school leaving certificate) exams. Sambadmedia.com.

Skelton, T. (2009). Children's geographies/geographies of children: Play, work, mobilities and migration. Geography Compass, 3(4), 1430-1448.

The Himalayan Times. (2010). Mass hysteria halts classes in Tanahu schools. News report on June 22. The Himalayan Times. Retrieved from http://www.thehimalayantimes.com/fullNews.php?headline= Mass+hysteria+halts+classes+in+Tanahu+school\&NewsID $=247573$ $\& a=3$

UNDP. (2015). Human development report 2015. New York, USA: United Nations Development Program.

WHO. (2007). Inter-agency agreement on mental health and psychosocial support in emergency settings. Bulletin of the World Health Organization, 81(11), 822. 10.1590/S004296862007001100002

Woodgate, R., \& McClement, S. (1998). Symptom distress in children with cancer: The need to adopt a meaning-centered approach. Journal of Pediatric Oncology Nursing, 15(1), 3-12. 